$\mathbb{H}_{\text {ปisgei }} \mathcal{A}$

ISSN: 1983 2435

\title{
Aposições oracionais em uso: rediscutindo fronteiras categoriais
}

\section{Clausal appositions in use: reopening discussions about category boundaries}

Márcia Teixeira Nogueira

marciatn@gmail.com

Universidade Federal do Ceará

RESUMO: Uma das propriedades mais associadas às construções apositivas é a sua natureza nominal, embora gramáticos e linguistas identifiquem aposições não nominais na fronteira com a coordenação e a subordinação. Com base teórica na Gramática Discursivo-Funcional (HENGEVELD; MACKENZIE, 2008; KEIZER, 2007), eu analiso a fronteira entre aposição e complementação em construções nas quais uma oração se encontra ligada aos substantivos fato, tese e desculpa por meio da preposição de.

PALAVRAS-CHAVE: Construção apositiva. Aposição. Complementação.

ABSTRACT: One of the properties mostly associated with appositive constructions is their nominal nature, although grammarians and linguists identify non-nominal appositions on the boundary between coordination and subordination. Based on Functional Discourse Grammar (HENGEVELD; MACKENZIE, 2008; KEIZER, 2007), I analyze the limits between apposition and complementation in noun constructions initiated by fato [fact], tese [thesis] and desculpa [excuse].

KEYWORDS: Appositive constructions. Apposition. Complementation.

\footnotetext{
* Professora Titular de Linguística do Programa de Pós-graduação em Linguística da Universidade Federal do Ceará.
} 


\section{Introdução}

Não são poucas as controvérsias em torno da definição e identificação de construções apositivas, destacando-se, no tratamento dessas construções, duas perspectivas: a de categorização discreta, que enquadra a aposição em um dos tipos de processo de construção pela adoção de critérios semânticos e sintáticos objetivos, e a consequente redução do conjunto de construções que podem ser analisadas como apositivas (TABOADA, 1978; LAGO, 1991; MARTINEZ, 1985; RODRIGUEZ, 1989; BURTON-ROBERTS, 1987); e a de categorização não discreta, que assume e investiga a fluidez categorial existente na aposição, propõe um conjunto de traços para identificação de uma representação prototípica dessa construção, mas identifica construções apositivas que se situam na fronteira com outras construções gramaticais da língua (MATTHEWS, 1981; MEYER, 1989, 1992; QUIRK et al., 1985; NOGUEIRA, 1999, 2012). Uma das características mais associadas às construções apositivas é a sua natureza nominal, embora gramáticos e linguistas reconheçam a existência de aposições não nominais que se encontram na fronteira com os processos sintáticos de coordenação e subordinação. Neste artigo, discuto a fronteira entre aposição e complementação na análise de construções em que uma oração explicita o conteúdo genericamente encapsulado por um nome e a ele se liga por meio de uma preposição. Essas construções assemelham-se às construções identificadas como that-apposition tratadas por Matthews (1981), Quirk et al (1985) e Meyer (1992).

Com base teórica na Gramática Discursivo-Funcional (HENGEVELD; MACKENZIE, 2008; KEIZER, 2007), que distingue, no Componente Gramatical, níveis e camadas de representação para análise dos atos discursivos, e na extensa literatura sobre o tema aposição, proponho uma análise de aspectos discursivos, semânticos e morfossintáticos que caracterizam a fronteira entre aposição e complementação, e sugiro representações que poderiam explicitar diferenças empíricas relevantes.

O modelo da Gramática Discursivo-Funcional (GDF) integra duas abordagens: o da estratificação descendente e a modular. Hengeveld e Mackenzie (2008) apontam uma diferença essencial da GDF em relação à Gramática Funcional (GF) de Simon Dik (1997): ao contrário do modelo da GF, que é ascendente (bottom up), um modelo de produção do discurso é descendente (top-down), ou seja, 
explicita que a geração de estruturas subjacentes e, em particular, as interfaces entre os vários níveis, podem ser descritas em termos das decisões comunicativas do Falante na produção do discurso. Para prover adequação tipológica, psicológica e pragmática à nova teoria, Hengeveld e Mackenzie distinguem quatro componentes: Conceitual, Contextual, Gramatical e Componente de Saída. No Componente Conceitual, estão as intenções comunicativas e as conceptualizações que demandarão formulação no Componente Gramatical. No Componente Contextual, encontram-se as informações que podem influenciar, de alguma forma, a formulação dos atos discursivos. Tal componente concerne ao contexto comunicativo em que se desenvolve a intenção comunicativa do falante.

É no Componente Gramatical que se dão as operações gramaticais de formulação e codificação. A formulação divide-se em três etapas: a seleção de esquemas que definem a hierarquia dos elementos e são preenchidos por lexemas do nível Interpessoal e do Representacional; a seleção desses lexemas, e a seleção de operadores que representam as distinções gramaticais requeridas em cada nível. A codificação, que resulta da formulação, manifesta-se nos níveis Morfossintático e Fonológico. Conforme esclarecem Hengeveld e Mackenzie, ao propor essa distinção entre as operações de formulação e codificação, a GDF se caracteriza como uma abordagem teórica da forma orientada da-função-para-a-forma (form oriented 'function-to-form'), o que não significa a consideração da simples passagem entre as intenções (cognitivas) e a codificação (linguística), já que o foco se encontra na concepção de gramática como o tratamento das distinções pragmáticas e semânticas que são sistematicamente refletidas na codificação morfossintática ou fonológica.

No nível Interpessoal, Hengeveld e Mackenzie (2008, p.50) consideram que "a maior unidade da interação relevante para a análise gramatical" é o Move (M), definida como uma contribuição autônoma para iniciar a interação e constitui "a menor unidade livre do discurso", caracterizada como a unidade que "ou é ou abre a possibilidade de uma reação". Um Move pode estar composto por um ou mais Atos Discursivos, que constituem "a menor unidade identificável de uma conduta comunicativa". Quando o Move é formado por dois ou mais Atos Discursivos, é possível reconhecer dois tipos de relação com base do status comunicativo que eles possuem: a equipolência (igual status comunicativo) e dependência (status comunicativo desigual), o que pode ser reconhecido pela função retórica que um ato 
desempenha em relação ao outro. Por sua vez, o Ato Discursivo pode ser constituído por, no máximo, quatro tipos diferentes de unidades: a llocução, os Participantes e o Conteúdo Comunicado. A llocução diz respeito às propriedades lexicais e formais do Ato Discursivo que podem ser atribuídas ao uso interpessoal convencionalizado na realização da intenção comunicativa. Já os participantes na interação, ganham formalização na alternância dos papéis de Falante ( $P 1)$ e Ouvinte (P2), cujas referências podem ser feitas por meio de vocativos, pronomes de primeira ou de segunda pessoa. O Conteúdo Comunicado, por sua vez, contém a totalidade do que o Falante deseja evocar na sua comunicação com o Ouvinte; portanto, é a unidade dentro da qual o mapeamento para o nível Representacional tem lugar. Cada Conteúdo Comunicado contém um ou mais Subatos, aos quais são atribuídas funções pragmáticas. Esses subatos podem ser de dois tipos: Atributivo $(T)$, para evocar uma propriedade; e Referencial $(R)$, para evocar um referente. Os autores distinguem referência de designação. A designação é de natureza categorial, pois diz respeito ao conteúdo semântico de uma unidade lexical, ou seja, à propriedade de um item lexical de designar entidades ontológicas, tendo, portanto, seu domínio no nível Representacional; a referência não é uma propriedade de um item lexical; ela concerne a uma decisão do falante de fazer referência a entidades como objetos do discurso. Desse modo, para os autores, a unidade um leão constitui uma representação semântica (relativa, portanto, ao nível Representacional) de uma entidade ontológica que pode ser usada referencialmente ("Eu vi um leão") ou atributivamente ("Este animal é um leão"). No primeiro caso, tem-se a instauração de um referente discursivo ou objeto do discurso; já no segundo, apenas se atribui uma propriedade a um animal.

Conforme Hengeveld e Mackenzie (2008), o nível Representacional está relacionado aos aspectos semânticos de uma expressão linguística, ou seja, ao modo pelo qual a língua(gem) se relaciona ao mundo extralinguístico que ela descreve, bem como aos significados de unidades lexicais e unidades complexas isoladas a partir dos modos como são usados na comunicação. É nesse nível que se encontram as "categorias semânticas" essenciais à função representacional da língua: o Indivíduo, entidade de primeira ordem, que pode ser localizada no espaço e pode ser avaliada em termos de sua existência; o Estado-de-coisas, entidade de segunda ordem, que pode ser localizada no espaço e no tempo e pode ser avaliada em termo de sua realidade; o Conteúdo Proposicional, entidade de terceira ordem, 
que constitui um construto mental, não podendo assim ser localizado nem no espaço nem no tempo, mas avaliado em termos de verdade; e a Propriedade (f), categoria que não tem existência independente e pode ser caracterizada em termos de sua aplicabilidade. O nível Representacional está também organizado de modo hierárquico e tem sua natureza determinada em parte pelo Nível Interpessoal. $\mathrm{O}$ núcleo básico da configuração padrão é o Estado-de-Coisas, caracterizado por uma Propriedade complexa ou Configuracional, que, por sua vez, é a combinação de unidades semânticas, que não se relacionam hierarquicamente. Os Estados-decoisas podem formar unidades tematicamente coerentes, chamadas de Episódios, que podem constituir uma extensão de Conteúdos Proposicionais, tidos como construtos mentais sobre um conjunto de Estado-de-Coisas. De acordo com Hengeveld e Mackenzie (2008, p. 144), os Conteúdos Proposicionais são construtos que não existem no espaço ou no tempo, mas existem na mente daqueles que os consideram. Eles podem ser factuais, quando são peças de conhecimento ou crenças sobre o mundo atual; ou não factuais, quando são desejos ou esperanças com relação ao mundo imaginário. Os Conteúdos Proposicionais podem ser qualificados em termos de atitudes proposicionais (certo, duvidoso, incerto) e/ou em termos de sua origem ou fonte (conhecimento compartilhado, evidência sensorial, inferência), por meio de modificadores ou operadores.

O nível Morfossintático do modelo da GDF inicia a consideração do processo de codificação linguística. É ele o responsável por receber o input dos outros dois níveis (Interpessoal e Representacional), fazendo-os emergir numa representação estrutural. Essa representação será codificada como um constructo fonológico no nível seguinte (nível Fonológico), que será input para o componente de articulação, o Componente de Saída ou Output do modelo. Embora esse nível seja dependente dos outros dois, ele aplica seus próprios princípios de organização.

\section{Um tipo particular de particular de aposição restritiva?}

Os estudos sobre o fenômeno da aposição revelam as dificuldades para reunir, em um único rótulo, as diferentes construções que costumam ser apontadas como apositivas.

De acordo com Quirk et al. (1985), uma aposição é restritiva quando os elementos em aposição estão em uma mesma unidade tonal, o que é indicado, no 
discurso oral, pela ausência de uma pausa ou, na escrita, de um sinal de pontuação entre os elementos apositivos. Para esses gramáticos, na aposição restritiva, os elementos apositivos constituem uma única unidade de informação. Alguns autores, mesmo argumentando em favor da inexistência teórica da aposição restritiva (BURTON-ROBERTS, 1987; LAGO, 1991; RODRIGUEZ, 1989), utilizam essa designação ao tratar do grupo de construções entre as quais incluímos as aposições oracionais aqui tratadas.

Keizer (2007, p. 22) reconhece que as construções apositivas restritivas não constituem um grupo homogêneo. Ela analisa, à parte, as construções apositivas com of, que costumam ser tratadas, por outros estudiosos do tema, como aposições restritivas ${ }^{1}$. Essas construções se aproximam de outras construções nominais com preposição que, também nas gramáticas de língua portuguesa, representam uma fronteira tênue e difícil com a modificação e a complementação, reveladas na identificação de alguns termos da Nomenclatura Gramatical Brasileira (NGB), tais como o aposto, o adjunto adnominal e o complemento nominal.

Como sabemos, um sintagma preposicionado (SP) pode funcionar como modificador ou como complemento de um núcleo, mas essa distinção nem sempre é fácil. Para Keizer, uma propriedade em comum entre as construções com complemento e com modificador é que, nesses casos, não há dúvida com relação ao núcleo, que será sempre a primeira unidade da construção. A diferença entre construções com complemento e construções com modificador reside na função (complemento ou adjunto) do SP e no estatuto da preposição (elemento lexical indicando posse, isto é, uma preposição "cheia"; ou elemento semanticamente vazio, um mero índice de função).

Por outro lado, nas construções apositivas com a preposição, nem sempre é fácil identificar o núcleo, já que os testes de permuta e supressão dos elementos apositivos revelam uma sentença resultante que é sintaticamente correta e semanticamente aceitável, já que ambos podem ser usados para referir uma mesma entidade. Em a cidade de Roma, tanto cidade como Roma (que é uma cidade), podem ser empregados para referir uma mesma entidade, com alterações apenas no nível discursivo.

\footnotetext{
${ }^{1}$ Quirk et al. (1985, p. 1284) referem tais construções como "appositions with of-phrases", onde o sintagma com a preposição não é analisado como um complemento do nome antecedente.
} 
Mesmo considerando graus de omissibilidade dos elementos da construção apositiva com a preposição, tal como no caso das aposições fechadas (close appositions), Keizer assume que, também nessas construções, os elementos não têm referência independente. $E$, mesmo considerando que o núcleo da construção é sempre o primeiro elemento nominal, a autora admite que a forma dessas construções varia bastante, a depender do tipo de elemento que the serve de especificação, isto é, do elemento que a preposição encabeça.

Keizer chama a atenção para o fato de que, nas aposições, o segundo elemento nominal é analisado como um predicado nominal, não como um SP, e que of não é representado como uma preposição encabeçando um SP (ou seja, a preposição não forma com o segundo elemento nominal um constituinte), mas é um elemento conectivo, um elemento funcional sem conteúdo semântico, inserido como meio sintático para indicar uma relação de especificação entre dois elementos nominais.

Analisando um conjunto de construções em que dois elementos nominais são ligados pela preposição of, Keizer (2007, p.83) propõe as seguintes representações subjacentes:

\section{a. Construções com núcleo-modificador}

the mosaics of Venice (os masaicos de Veneza)

[sN [Det the] [ExtN [N mosaics] [sp [p of] [sN [N Venice]]Poss]]]

\section{b. Construções com núcleo-complemento}

the production of penicillin (a produção de penicilina)

[SN [Det the] [ExtN [N production] [SP [P Of] [SN [N penicillin]] Pat]]]

the father of the bride (o pai da noiva)

[SN [Det the] [ExtN [N father] [sP [P of] [sN [Det the ] [Nbride]]] Ref]]

\section{c. Construções partitivas}

one of the stallholders (um dos vendedores)

[sN [Num one] [ExtN [N e] [sP [P of] [sN [Det the] [N stallholders]] Ref]]] 
most of his plays (a maioria dos jogos)

[sN [Q most ] [ExtN [N e] [sP [P of] [sN [Det his ] [N plays]] Ref]]]

\section{d. Construções com núcleo-qualificador}

a book of comics (um livro de humor)

[sN [Det a ] [N book [sP [P of] [N Comics]]]]

a word of gratitude (uma palavra de gratidão)

[sN [Det a ] [N word [sP [P of] [N gratitude]]]]

\section{e. Aposições com of}

the city of Rome (a cidade de Roma)

[sN [Det the ] [ExtN [N-head city] [EL of] [N Rome]]]

his role of military leader and negotiator (seu papel de líder militar e negociador)

[SN [Det his ] [ExtN [N-head role] [EL of] [ExtN [[[A military] [N leader]] and [N negotiator]]נ]]

Nas construções com núcleo-modificador, o primeiro elemento nominal não é derivado (isto é, não há um verbo cognato) e não é relacional (isto é, não é um nome transitivo). Semanticamente, a natureza da relação é de posse em seu sentido mais amplo. Nas construções com núcleo-complemento, o núcleo é tipicamente um nome relacional (transitivo), e o elemento of, mesmo esvaziado de sentido, pode ser considerado uma preposição. Nesse tipo de construção, os nomes cognatos de verbos transitivos são vistos igualmente como transitivos (relacionais), nomes com valência semântica (em relações parte-todo, parentesco, atributo-todo). Nas construções partitivas, o SP funciona como complemento do nome e a relação é tipicamente de inclusão (parte-todo, membro-conjunto). Nas construções com núcleo-qualificador, o SP não é referencial, e o segundo elemento nominal é, em geral, um nome massivo. Nas construções apositivas com of, o primeiro elemento nominal funciona como núcleo, e o segundo, como um elemento nominal que especifica ou restringe esse núcleo. $O$ elemento relacional of não forma com o nome que o segue um constituinte, sendo analisado por Keizer como um elemento distinto 
da preposição, com função conectiva puramente sintática. A autora enfatiza que, como nos casos das aposições restritivas em geral, nenhum dos dois elementos é referencial, mas ambos podem ser usados de forma independente para se referir a uma mesma entidade.

As construções apositivas restritivas em língua portuguesa apresentam algum elemento conectivo (preposição, conjunção) entre os dois elementos nominais. A maior parte dessas construções aproxima-se do que Keizer (2007) tratou como aposições com of. Como vimos, nem sempre é fácil distinguir entre esse tipo de construção apositiva restritiva e as construções com núcleo-modificador (os mosaicos de Veneza), núcleo-complemento (a produção de penicilina), núcleoqualificador (um livro de humor) e construções partitivas (um dos vendedores). Apesar de algumas diferenças relativas à natureza do nome nuclear (relacional ou não) e do papel da preposição nessas construções, o fato de analisarmos o segundo elemento nominal como aquele que especifica o primeiro elemento (e não o contrário) aumenta ainda mais a semelhança entre elas. A esse respeito, identifico como construções apositivas restritivas alguns exemplos fornecidos por gramáticos, tais como A ilha de Marajó (MACIEL, 1916); A cidade de Roma (GOMES,1930); O título de barão (JOÃO RIBEIRO, 1933), entre outros.

Embora as aposições oracionais não sejam tratadas por Keizer, faço aqui uma tentativa de estender essas considerações da autora à análise de exemplos de aposição restritiva fornecidos por gramáticos e linguistas da língua inglesa, e que podem ser traduzidos como estruturas correntes no português. Neles uma oração introduzida por that liga-se a nomes como fact (fato), idea (ideia) e excuse (desculpa), como em:

(1) The fact that he is leaving (MATTHEWS, 1981, 231).

( $O$ fato de que ele está partindo.)

(2) The idea that cats can't fly is true. (MEYER, 1989,161).

(A ideia de que gatos não podem voar é verdade.)

(3) She rejected their excuses, even this last one, that investigations had taken several weeks (QUIRK et al., 1985, 1305).

(Ela rejeitou suas desculpas, mesmo esta última, de que as investigações teriam levado várias semanas.) 
Segundo Matthews (1981), se a oração do exemplo (1) for vista como um complemento do nome, a análise estará relacionada a uma questão de valência desse nome. Assim, observamos que é possível, por exemplo, dizer-se The fact that he is leaving ( $O$ fato de que ele está partindo), mas não se pode dizer The happening that he is leaving ( $O$ acontecimento de que ele está partindo). Matthews lembra que, assim como ocorre com os verbos, os nomes podem ou não excluir a realização de orações completivas, dependendo de sua valência. Lembra, ainda, que, em muitos casos, as valências de nomes e verbos estão lexicalmente relacionadas.

Todavia, Matthews ressalta que a restrição de alguns nomes à realização de uma oração a eles associada pode ser cancelada, caso a oração esteja separada como um grupo tonal, tal como se observa em: Did you heard the ending, that they got married on Saturday? (Você ouviu falar no desfecho, de que eles casaram no sábado?). Com uma pausa, estaríamos, portanto, diante de uma aposição, em que um sintagma nominal é expandido ou explicado através de uma oração. Entretanto, alguns nomes admitem igualmente a realização de uma oração marcada ou não por uma fronteira entonacional, tal como acontece em: Have you heard the latest news, that Bill is leaving? (Você ouviu a última novidade, de que Bill está partindo?) ou Have you heard the latest news that Bill is leaving? (Você ouviu a última novidade de que Bill está partindo?). Como o substantivo não tem natureza valencial, Matthews conclui que, nesses casos, não se trata de uma complementação a tais nomes, mas, simplesmente, da particularidade que eles têm de admitir tanto a aposição fechada de Bloomfield (close apposition), quanto a forma mais "frouxa" de aposição (loose apposition).

Segundo Matthews, se houvesse substantivos com os quais a oração fosse essencialmente obrigatória, a hipótese de complementação estaria fortalecida. Entretanto, o autor observa que, em geral, não é o que acontece. Em frases como The fact that he is leaving ( $O$ fato de que ele está partindo), o substantivo não tem nenhuma nuance verbal. Para o autor, o dilema permanece: se for considerado que há apenas uma expressão referencial numa construção que estaria incompleta, caso a oração estivesse ausente, tem-se uma relação de complementação; todavia, se o nome fact for analisado como uma expressão referencial, e a oração that he is leaving for vista como um reforço subsidiário para a identificação, nós estaremos diante de um caso de aposição. 
A construção que temos em (2) assemelha-se à do exemplo anterior, pois também ilustra o que Matthews (1981) e Meyer (1989) consideram como uma fronteira entre aposição e complementação. Ilustra, ainda, o que Quirk et al. (1985) analisam como um caso de aposição parcial e fraca entre um sintagma nominal e uma oração. Nesse tipo de construção, não é possível suprimir a primeira unidade, nem inverter a ordem. À semelhança do que temos em (1), a construção se aproxima do tipo de estrutura que instancia a relação lógico-semântica de projeção (HALLIDAY, 1985), em que o conteúdo descrito na oração cats can't fly (gatos não podem voar) é projetado como uma ideia (poderia ser uma tese, hipótese, opinião etc). A oração é vista por Halliday como estrutura encaixada que funciona como um elemento pós-modificador no grupo nominal.

Com base nas diferenças apontadas por Keizer entre construções apositivas com of e construções de núcleo-modificador e de núcleo-complemento, bem como nas discussões feitas por Matthews (1981), Quirk et al. (1985) e Meyer (1992) sobre essa indeterminação de fronteira categorial, analiso, neste estudo, ocorrências do que poderíamos considerar como usos semelhantes a (1), (2) e (3), em textos jornalísticos do português brasileiro contemporâneo.

\section{Metodologia}

O foco desta análise é um tipo de construção em que uma estrutura oracional explicita o conteúdo genericamente apresentado por um substantivo e a ele se liga por meio da preposição $d e^{2}$. Essa estrutura ilustra a fronteira entre uma aposição restritiva e uma construção de núcleo-complemento.

Identifico, nesse tipo de construção, uma semelhança com as estruturas que instanciam a relação lógico-semântica de projeção, tal como proposta por Halliday (1985, 2004). Na projeção, um grupo ou oração projeta-se por meio de outra que a apresenta como um fato, uma ideia ou uma locução. Realizei buscas textuais, na internet, para identificação, em textos jornalísticos, de ocorrências com os nomes fato, tese e desculpa, que corresponderiam, a princípio, a três categorias de representação nos níveis da GDF: Estado-de-coisas e Conteúdo Proposicional (nível Representacional) e Conteúdo Comunicado (nível Interpessoal).

\footnotetext{
${ }^{2}$ Utilizaremos o termo preposição, indistintamente, para designar o elemento de nas estruturas apositivas e assemelhadas.
} 
Todas as ocorrências têm em comum a inexistência de pausa entonacional entre nome e oração, o que não necessariamente está relacionado com o critério de omissibilidade e/ou referencialidade do nome nuclear. As ocorrências foram analisadas conforme os parâmetros discutidos por Keizer (2007) em relação às aposições com of, e de acordo com as propriedades apontadas por Matthews (1981), Quirk et al. (1985) e Meyer (1992) na discussão sobre a fronteira entre aposição e complementação. Em cada ocorrência, observei se: a) o elemento nominal tem verbo cognato; b) o elemento nominal é transitivo, relacional, tem alguma valência semântica (relações parte-todo, parentesco, atributo-todo); c) a preposição é esvaziada de sentido ou empresta algum valor semântico à construção ${ }^{3}$; d) a oração é essencialmente obrigatória; e) o nome é essencialmente obrigatório.

\section{Análise e discussão: rediscutindo os limites entre aposição e complementação}

\subsection{Fato}

Passemos à análise das seguintes ocorrências com o nome fato:

(4) O policial diz que hoje as armas dos criminosos são mais potentes. Ele exemplifica com o fato de que, neste ano, foram apreendidos 56 fuzis pela polícia, contra 12 em 2005. (folhauol/16/10/2017). ${ }^{4}$

(5) Ainda não aceitamos o fato de que o aprendizado ocorre no trabalho. (UOL/opinião- 21/03/2015). ${ }^{5}$

(6) $O$ deputado parece ignorar o fato de que todas as leis devem respeitar a Constituição. (theintercept/28.09.2017). ${ }^{6}$

Segundo Keizer (2007), nas construções de núcleo-complemento, ao contrário das aposições com preposição, os nomes são cognatos de verbos

\footnotetext{
${ }_{4}^{3}$ Há também o uso de conjunções, como em: A dúvida se deveria ou não esperar.

4 http://temas.folha.uol.com.br/mapa-da-morte/jovens-vitimas/policia-de-alckmin-mata-1-adolescentepor-semana-na-cidade-de-sao-paulo.shtml

${ }^{5}$ https://noticias.uol.com.br/opiniao/coluna/2015/03/21/ainda-nao-aceitamos-o-fato-de-que-o-aprendiza do-ocorre-no-trabalho.htm

${ }^{6}$ https://theintercept.com/2017/09/28/as-ironias-e-contradicoes-do-deputado-que-quer-mudar-a-consti tuicao-para-criminalizar-o-aborto/
} 
transitivos, portanto são vistos igualmente como transitivos (relacionais). O nome fato não tem verbo cognato, o que não é, todavia, suficiente para decidirmos sobre sua natureza não relacional. Há nomes valenciais sem verbos cognatos, como vontade, apetite, medo, que costumam ser usados em construções com verbosuporte

Nos exemplos (4) e (5), fato tem significado mais próximo da categoria Estado-de-coisas, isto é, da designação de um evento (- neste ano, foram apreendidos 56 fuzis pela polícia, contra 12 em 2005/ - o aprendizado ocorre no trabalho), sendo esse fato utilizado como premissa para um argumento. ${ }^{7}$ No exemplo (6), no entanto, como em muitas outras ocorrências do corpus analisado, o nome fato passa a encapsular conteúdos que, na verdade, têm natureza semântica de Conteúdo Proposicional, sendo possível, por exemplo, a substituição de fato por ideia ou tese.

(6a) O deputado parece ignorar a ideia de que todas as leis devem respeitar a Constituição.

Todavia, em nenhum desses casos aqui apresentados, há razões para identificarmos algum tipo de valência semântica no uso do nome fato.

Quanto à preposição que encabeça a oração, ela funciona como elemento meramente morfossintático, o que é comum nos casos de aposições especificativas como $A$ cidade de Paris. Apesar da semelhança morfossintática com a relação de núcleo-complemento e de núcleo-modificador, a relação semântica entre o nome fato e o conteúdo da oração que a ele se liga tem a natureza próxima de uma relação de equivalência, nos termos de Quirk et al (1985) e de Meyer (1992), uma relação tipicamente associada às construções apositivas. Em outras palavras, assim como, ao dizermos $O$ mês de maio, estamos nos referindo a um mês que é maio (mês=maio), o que seria diferente, por exemplo, se disséssemos $O$ mês das noivas (mês $\neq$ as noivas), nas ocorrências aqui analisadas, há uma relação de predicação. Evidência para essa análise encontra-se no uso, não tratado neste estudo, de predicações em que essa relação de equivalência se enuncia.

\footnotetext{
${ }^{7}$ Cf. A nova retórica (PERELMAN; OLBRECHTS-TYTECA, 1996).
} 
(7) O fato é que de maneira inexplicável, tais temas viram assunto quase obrigatório em todas as iniciativas de aprendizagem. (UOL/Opinião- 21/03/2015) ${ }^{8}$

A decisão quanto à omissibilidade da oração nos exemplos de (4) a (6) nos deslocou, inevitavelmente, do terreno das especulações sobre a valência semântica do nome fato, para o da análise do fluxo de informação, isto é, para o âmbito das funções pragmáticas. Nas aposições restritivas nominais, Keizer identifica o primeiro nome como o núcleo e o segundo, como um modificador que especifica ou restringe esse núcleo, sendo apenas o conjunto analisado como referencial, embora ambos possam ser usados separadamente em atos de referência. Nos exemplos aqui analisados, não é possível omitir-se a oração, pois é nela que se codifica a informação focal que, segundo Hengeveld e Mackenzie (2008, p. 89), sinaliza a seleção estratégica de informação nova pelo Falante. Sendo um nome genérico, fato apenas institui essa informação contida na oração como um Tópico sobre o qual algo será predicado. Em alguns casos, esse nome é, inclusive, dispensável:

(5a) Ainda não aceitamos que o aprendizado ocorre no trabalho.

(6b) O deputado parece ignorar que todas as leis devem respeitar a Constituição.

Voltando à análise do uso do nome fato como encapsulador de um evento, isto é, do conteúdo da oração seguinte como um acontecimento, sugiro que, no nível Interpessoal, toda a construção, em exemplos como (4) e (5), seja analisada como um subato referencial constituído por um subato referencial (nome genérico) que encapsula e rotula como fato (estado-de-coisa), outro subato referencial, relativo ao conteúdo da oração a seguir. No nível Representacional, temos dois estados-decoisas, em que o segundo especifica o primeiro.

Há casos, como dissemos, em que o nome fato não parece rotular o conteúdo da oração seguinte como um fato, isto é, como um acontecimento. Essa perda de traços semânticos do nome, bem como a reanálise na expressão o fato (e não um fato, por exemplo) são indícios de um processo de gramaticalização. Ao comentar que Heine \& Reh notaram que, quanto mais gramaticalizada estivesse uma forma,

8 https://noticias.uol.com.br/opiniao/coluna/2015/03/21/ainda-nao-aceitamos-o-fato-de-que-o-aprendi zado-ocorre-no-trabalho.htm 
mais ela perderia em pragmática e ganharia em relevância sintática, Hopper (1996, p. 222) lembra que o uso de the fact (o fato) consiste numa estratégia para apresentar um conteúdo oracional como verdadeiro, ou seja, a verdade da oração é garantida pela presença da palavra fact (fato). Hopper informa, contudo, que, em algumas variedades do inglês falado, the fact tornou-se um recurso gramatical, sem qualquer atribuição de status de factualidade ao conteúdo que o segue. Esse processo de gramaticalização pode estar relacionado, também, à alta frequência de uso do nome fato como encapsulador de conteúdos oracionais.

O uso do nome fato seguido de uma oração constitui, nesses casos, apenas um recurso de encapsulamento para conferir referencialidade ao conteúdo de uma oração e assim possibilitar a realização de subatos atributivos sobre esse conteúdo. Mais do que a rotulação desse conteúdo como uma das categorias do nível Representacional, o uso de fato constitui, nesses casos, um expediente morfossintático que se aproxima da funcionalidade, por exemplo, de um pronome indefinido ou demonstrativo.

\subsection{Tese}

Seguem alguns exemplos do uso do nome tese em aposições restritivas oracionais na fronteira da complementação.

(8) Dia de ontem derrubou a tese de que acusados são perseguidos. (oglobo.globo.com/14.09.2017) ${ }^{9}$

(9) Riva desiste de habeas corpus e reforça tese de que fez delação premiada. (gazetadigital/20.09.2017) ${ }^{10}$

Nos exemplos acima, tese é nome abstrato de estado e não tem verbo cognato, o que reforça a análise desse tipo de construção como apositiva, e não como um caso de núcleo-complemento. Ainda assim, nessa acepção de ideia ou proposição defendida, esse nome genérico pressupõe a presença de uma especificação sobre qual seria a tese, isto é, o conteúdo que, em geral, se encontra

\footnotetext{
9 http://blogs.oglobo.globo.com/miriam-leitao/post/dia-de-ontem-derrubou-tese-de-que-acusados-saoperseguidos.html

${ }_{10} \mathrm{http}: / /$ www.gazetadigital.com.br/conteudo/show/secao/149/og/1/materia/521198/t/riva-desiste-dehabeas-corpus-e-reforca-tese-de-que-fez-delacao-premiada
} 
expresso por uma oração. Por esse motivo, temos uma relação mais próxima da equivalência típica das aposições (tese = acusados são perseguidos).

À semelhança do que propus no exemplo anterior, identifico aqui um subato referencial constituído por um subato referencial (nome genérico e não relacional) que encapsula e rotula, como uma tese (Conteúdo Proposicional), o conteúdo da oração seguinte. No nível Representacional, teríamos dois Conteúdos Proposicionais dentro de um Conteúdo Proposicional.

O exemplo (10), a seguir, é de uma manchete em que o nome ideia é o núcleo encapsulador do conteúdo de uma oração:

(10) Ideia de que ciência e religião sejam inimigas não resiste à análise histórica (folha.uol/13.09.2017) ${ }^{11}$

O nome ideia tem verbo cognato registrado no Dicionário de Usos do Português do Brasil (BORBA, 2002) - idear, verbo de ação-processo, com o significado de idealizar, criar na ideia, imaginar. Com essa acepção de açãoprocesso, este verbo parece ter sentido equivalente ao da construção com verbosuporte fazer ideia, de uso mais frequente do que idear, como temos em (11):

(11) Christopher Nolan não fazia ideia de que Harry Styles era tão famoso antes de filme. (folhadoestado.com.br/10.07.2017) ${ }^{12}$

Nesse tipo de construção com verbo-suporte, o substantivo empresta seu significado na formação de um Predicado (Propriedade), não sendo referencial. Essa perda de referencialidade não parece ocorrer no uso de uma aposição restritiva, já que, na aposição, o nome ideia tem proeminência em sua função discursiva de evocar um referente. Em outras palavras, a funcionalidade do nome ideia é conferir referencialidade a um conteúdo que será tratado como Tópico. O verbete destinado ao nome ideia nesse mesmo dicionário apresenta-o como abstrato de estado, e a acepção mais próxima do que encontramos no exemplo (10) é o de ideia como conceito ou noção, para a qual o verbete prevê a realização de um complemento

\footnotetext{
${ }^{11} \mathrm{http}: / /$ www1.folha.uol.com.br/ilustrissima/2017/09/1917894-a-religiao-nao-vai-desaparecer-e-a-cien cia-nao-vai-acabar-com-ela.shtml

${ }^{12} \mathrm{http}: / /$ www.virgula.com.br/tvecinema/christopher-nolan-nao-fazia-ideia-de-que-harry-styles-era-taofamoso-antes-de-filme/\#img=1\&galleryld=1224768
} 
(Nome ou Oração) mediado pela preposição. É nesse tipo de construção com o nome ideia que identificamos uma construção apositiva, tendo em vista que é nessa acepção que a oração, em vez de complemento da construção com verbo-suporte fazer ideia, especifica uma noção, crença ou opinião, em outras palavras, um Conteúdo Proposicional sobre o qual se predica algo. Com esse tipo de aposição, o conteúdo da oração (ciência e religião são inimigas), ao ser encapsulado, projetado e rotulado pelo nome ideia, pode ser alvo do subato atributivo que se segue (não resiste à análise histórica).

\subsection{Desculpa}

Seguem duas ocorrências com o uso do nome desculpa seguido de uma oração.

(12) Com a desculpa de que o formato é "ergonômico", O Popular vira tabloide para tentar se salvar da derrocada do jornal impresso em todo o mundo. (Goiás24horas/03.04.2016). ${ }^{13}$

(13) Janot não pode nem usar a desculpa de que o encontro era "conversa de bêbado" porque não estava bebendo. (jornallivre/10.09.2017) ${ }^{14}$

Nos exemplos (12) e (13), temos o nome desculpa com acepção de pretexto, evasiva. O nome tem verbo cognato, desculpar, embora este tenha o sentido de perdoar, isentar de alguma culpa. Com a acepção de apresentar uma falsa justificativa para algo, uma construção com verbo-suporte dar (dar desculpa) pode ser usada. Nesse caso, o nome desculpa não está associado a um verbo ou adjetivo cognato, aproximando-se do que Borba (1996) considera como nome abstrato autônomo, à semelhança de vontade, idade, dieta etc. Esses nomes autônomos podem estabelecer, com o sintagma preposicionado que os segue, relações semânticas do tipo parentesco, parte-todo ou membro-conjunto (vontade de cantar, dieta de arroz). Esse não parece ser o caso das ocorrências em (12) e (13), já que a oração que se segue ao nome não se comporta como um complemento do nome

\footnotetext{
${ }^{13}$ http://goias24horas.com.br/53641-com-desculpa-de-que-o-formato-e-ergonomico-o-popular-vira-ta bloide-para-tentar-se-salvar-da-derrocada-do-jornal-impresso-em-todo-o-mundo/

${ }_{14}$ https://jornalivre.com/2017/09/10/janot-nao-pode-nem-usar-a-desculpa-de-que-o-encontro-era-con versa-de-bebado-porque-nao-estava-bebendo/
} 
desculpa, mas estabelece, com ele, uma relação de predicação do tipo identificada em aposições restritivas especificativas (a desculpa é que o formato é "ergonômico"; a desculpa é que o encontro era "conversa de bêbado").

Temos, portanto, em (12) e (13), ocorrências que ilustram a fronteira entre aposição restritiva com a preposição e a estrutura núcleo-complemento. Dessa vez, o conteúdo da oração é encapsulado, rotulado e projetado como um ato de fala (desculpa, mas poderia ser, por exemplo, explicação, justificativa etc), ou seja, como um Conteúdo Comunicado, já que diz respeito não ao encapsulamento de um conteúdo proposicional, mas ao que se faz com ele, daí sua natureza acional, própria do nível Interpessoal. De acordo com Hengeveld \& Mackenzie (2008, p. 257277), as categorias dos quatro níveis do Componente Gramatical (Interpessoal, Representacional, Morfossintático e Fonológico) podem alimentar diretamente o Componente Contextual e, uma vez armazenadas nesse Componente, podem influenciar a formulação de mensagens posteriores. Assim, unidades desses níveis podem ter representação no Nível Representacional e, como já foram produzidas, são analisadas como uma referência de natureza metalinguística. Para os autores, em princípio, todas as unidades interpessoais, morfossintáticas e fonológicas podem, assim, entrar no Nível Representacional. Parece ser o caso das ocorrências em (12) e (13), que analisamos como um único subato referencial constituído por um subato referencial (desculpa) que encapsula e rotula, como um Conteúdo Comunicado, o conteúdo da oração seguinte. No nível Representacional, teríamos dois Conteúdos Comunicados dentro de um único Conteúdo Comunicado.

Análise semelhante poderia ser proposta para os casos de aposição restritiva com nomes relativos a atos ilocucionários como declaração, anúncio, denúncia, como nos exemplos a seguir.

(14) Pastores aprovam a Declaração de Fé das Assembleias de Deus. Entre os pontos apresentados está a declaração de que casamento é apenas a união entre um homem e uma mulher. (jmnoticia.com.br/28.04.2017) ${ }^{15}$

(15) As ações da Eletrobrás saltaram quase $50 \%$ após o anúncio de que o governo pretende desestatizar a companhia. (agenciabrasil.ebc.com.br/ 23.08.2017) $)^{16}$

\footnotetext{
${ }^{15}$ http://www.jmnoticia.com.br/2017/04/28/pastores-aprovam-declaracao-de-fe-das-assembleias-dedeus/
} 
(16) 'É mentirosa', reage Dilma à denúncia de que pediu dinheiro a Odebrecht. (correio24horas/19.10.2017). ${ }^{17}$

Nesses casos exemplificados nas ocorrências de (14) a (16), há uma fronteira entre aposição e complementação ainda mais indeterminada, visto que os nomes abstratos de ação declaração, anúncio, denúncia têm verbos cognatos (declarar, anunciar e denunciar) e há um paralelismo entre os conteúdos da oração após esses nomes e os respectivos complementos objetivos numa relação com esses verbos cognatos.

\section{Considerações finais}

As indeterminações de fronteira categorial entre as aposições restritivas oracionais e os casos de complementação discutidos neste estudo reforçam a ideia de que a aposição não pode ser identificada segundo um único critério.

Se assumirmos com Halliday (1985) que a aposição é antes uma relação lógico-semântica de expansão por elaboração (=), quando um elemento expande outro, reformulando-o, especificando-o em mais detalhes, tipicamente instanciada por meio de uma relação paratática, podemos compreender que, a depender de cada contexto e da interveniência de fatores de ordem hierarquicamente superior (textual-discursivos), a identificação dessa relação semântica de equivalência é possível, ainda quando a codificação se aproxima da estrutura sintática de um encaixamento (embedding).

No entanto, é preciso observar que, se as construções aqui analisadas apresentam entre o núcleo nome (fato/tese/desculpa) e o conteúdo da oração que a ele se segue, uma relação de equivalência, o expediente textual-discursivo nelas identificado é antes o de uma projeção, nos termos de Halliday, de um fato, ideia ou locução. E é essa natureza de projeção, que envolve estratégias textualizadoras, sobretudo ligadas à nominalização (encapsulamento e rotulação), bem como à integração do texto jornalístico escrito, que parece motivar a codificação desse tipo

\footnotetext{
16 http://agenciabrasil.ebc.com.br/economia/noticia/2017-08/acoes-da-eletrobras-sobem-quase-50apos-anuncio-de-desestatizacao

17 http://politica.estadao.com.br/blogs/fausto-macedo/e-mentirosa-reage-dilma-a-denuncia-de-quepediu-dinheiro-a-odebrecht/
} 
de aposição restritiva oracional numa estrutura assemelhada à de núcleocomplemento.

\section{Referências}

BORBA, F. S. Dicionário de usos do português do Brasil. São Paulo: Ática, 2002.

DIK, Simon C. The Theory of Functional Grammar, vol. 1, ed. by HENGEVELD (Kees). Berlin/New York: Mouton de Gruyter, 1997.

HALLIDAY, M. A. K. An introduction to functional grammar. London: Edward Arnold, 1985.

HENGEVELD, K.; MACKENZIE, J. L. Functional Discourse Grammar: a typologicallybased theory of language structure. Oxford: Oxford University Press, 2008.

MATTHEWS, P. H. Syntax. New York: Cambridge University Press, 1981.

KEIZER, M. E. The English Noun Phrase - The Nature of Linguistic Categorization, Cambridge: Cambridge University press, 2007.

MEYER, C. F. Restrictive apposition: an indeterminate category. Netherlands, English-Studies, 70, 2, 1989, p. 147-166. 1992.

Apposition in contemporary English. New York: Cambridge University Press,

QUIRK, R. et al. A compreensive grammar of the English language. London/New York: Longman, 1985. 